\title{
Prostate cancer invasion is influenced more by expression of a CD44 isoform including variant 9 than by Muc18
}

\author{
Archangel Levi Omara-Opyene ${ }^{1}$, Jingxin Qiu ${ }^{1}$, Girish V Shah ${ }^{2}$ and Kenneth A Iczkowski ${ }^{1,3}$ \\ ${ }^{1}$ Department of Pathology, Immunology, and Laboratory Medicine, The University of Florida, Gainesville, FL, \\ USA; ${ }^{2}$ Department of Pharmaceutical Sciences, University of Louisiana, Monroe, LA, USA and ${ }^{3}$ Department \\ of Pathology and Laboratory Medicine, Veterans Administration Medical Center, Gainesville, FL, USA
}

\begin{abstract}
The standard form of cell adhesion glycoprotein CD44 is a metastasis suppressor in prostate cancer. However, we previously showed by RT-PCR and Western blotting that cancer overexpresses unique CD44 variant v7-v10 isoforms. Muc18 is another cell adhesion marker reportedly overexpressed by prostate cancer. Matched frozen section-confirmed tumor and benign tissues were harvested from 10 prostatectomy specimens and tumor was microdissected from two lymph node metastases. Tissues were homogenized for RNA preparations, and RTPCR was performed for the CD44v7-v10 sequence. In cultured prostate cancer cells, we caused RNA interference against CD44v9 and/or Muc18. We used PC3M cells and a derivative cell line called $G_{s} \alpha$, that constitutively expresses this G-protein and is more invasive. Lipofection was performed for a green fluorescent protein plasmid and for two 22-mer DNA fragments, cloned into a plasmid expression vector to generate hairpin, interfering dsRNA. Assays for invasion into Matrigel, a basement membrane matrix, were performed in 4-5 experiments. RT-PCR demonstrated expression of a 608 bp band representing CD44v7-v10 or a 638 bp band of CD44v6-v10 in prostate cancer tissues and metastases but not benign tissue. Cultured $\mathrm{G}_{\mathrm{s}} \alpha$ cells overexpressed CD44v9 by comparison with PC3M cells. At $90 \mathrm{~h}$ after 6-hour lipofection, protein silencing was evident by Western blots. Silencing the CD44v9 expression reduced invasiveness into Matrigel to $21.6 \pm 7.0 \%$ in PC3M cells $(P<0.001)$ and $31.2 \pm 18.3 \%$ in $G_{s} \alpha$ cells $(P=0.001)$, compared to cells exposed to transfection vehicle alone. Silencing Muc18 expression reduced invasiveness to $76.9 \pm 13.5 \%$ of the control value in PC3M cells $(P<0.05)$ and $84.8 \pm 29.9 \%$ in $G_{s} \alpha$ cells $(P=0.18)$. Prostate cancer invasion is facilitated more by its overexpression of CD44 variant 9 than by Muc18. Its relative overexpression by $G_{s} \alpha$ cells is a novel finding, suggesting a link between signal transduction and cell adhesion marker expression.
\end{abstract}

Laboratory Investigation (2004) 84, 894-907, advance online publication, 26 April 2004; doi:10.1038/labinvest.3700112

Keywords: CD44; Muc18; prostate cancer; RNA interference; matrigel invasion

Prostate cancer remains a public health problem of enormous magnitude; it is the second most common cause of cancer fatality among North American men and the most common in Great Britain. Only a minority of all cases invade locally and metastasize, thus requiring altered expression of cell adhesion molecules

Correspondence: Dr KA Iczkowski, MD, Pathology and Laboratory Medicine Service (113), Veterans Administration Medical Center, 1601 SW Archer Road, Gainesville, FL 32608-1197, USA.

E-mail: iczkoka@pathology.ufl.edu

This paper was presented in poster form at 2004 Annual Meeting of the American Association for Cancer Research, Orlando, FL, 31 March 2004.

Received 17 January 2004 revised and accepted 8 March 2004; published online 26 April 2004 to allow tumor cell detachment, migration through a stromal matrix, and lymphovascular invasion.

CD44, a family of transmembrane glycoproteins involved in homotypic cell, cell-matrix, and cellcytoskeletal interaction, holds promise as a prostate tumor marker. The extracellular domain of CD44 binds numerous matrix substituents: hyaluronic acid, heparin-affinity growth factors, vascular endothelial growth factor, p185 $185^{\mathrm{HER} 2}$, epidermal growth factor, and hepatocyte growth factor. Its intracellular domain binds to ezrin, radixin, moesin and merlin, which interact with the cytoskeleton; notably, neutral endopeptidase 24.11 competes with CD44 for this interaction. ${ }^{1}$ CD44 also binds directly to the cytoskeletal substituent ankyrin, thus determining cell and tissue architectural form. ${ }^{2}$ CD44 is an oncodevelopmental protein, with roles in 
embryogenesis and tumor metastasis. The CD44 gene, which maps to chromosome 11 , contains 20 exons spanning $60 \mathrm{~kb}$, and can be subdivided into five structural domains. CD44 can assume several isoforms (Figure 1). Exons 1-5 and 16-20, termed standard (CD44s), form an $89 \mathrm{kDa}$ protein expressed mainly on cells of hematopoietic origin, where they facilitate lymphocyte homing. ${ }^{3,4}$ Longer, variant isoforms (CD44v1-v10) include one or more of exons 6-15 spliced in, although in humans, exon 6 (v1) is not expressed. Splice variants are expressed by some normal epithelial cells in a tissue-specific manner and CD44v10 is expressed by normal lymphocytes. ${ }^{5}$ Cancers express novel variant isoforms, reflecting deregulated mRNA splicing. Alternative splicing to produce variant exons takes place in the membrane-proximal extracellular domain and the cytoskeletal tail, and the cell's microenvironment influences this process. The sizes of CD44 protein expressed in different cell types thus range up to $120 \mathrm{kDa}^{1,4}$ Theoretically, inclusion of all variant exons would yield a protein of molecular weight $230 \mathrm{kDa}$, but most variant isoforms are less than $120 \mathrm{kDa}$. Cleavage mediated by metalloproteinases occurs in the membraneproximal extracellular domain. Okamoto et $a l^{6-8}$ have recently shown that, in several human tumors (exclusive of prostate cancer), cleavage products of $25-30 \mathrm{kDa}$ are detectable by Western blot using antibody against the cytoplasmic portion of CD44. The soluble portion of CD44 has been detected in serum as a $100-160-k D a$ fragment using anti-CD44v monoclonal antibodies to extracellular portions of the molecule. ${ }^{9}$ Western blot detection of CD44

Figure 1 Splice variant CD44 exons are situated in the extracellular domain. CD44v1 is expressed in rats and mice but contains a stop codon and thus it is silent in humans. The entire variant region may be PCR-amplified with primers such as P1 and P2. Portions may also be amplified with other primer sets such as our E3 and P4, which amplifies v7-v10. Transcripts 1730 bp long have been described, containing CD44v2-v10, in ductal breast carcinoma. ${ }^{17}$ (a) Expression of a v3-containing isoform occurs in head and neck squamous cell carcinoma. ${ }^{18}$ (b) An isoform with v3 and v8-v10 spliced is the predominant form expressed in ductal breast carcinoma. ${ }^{16}$ (c) Expression of CD44v4-v5 isoforms is implicated in binding of tumor cells to hyaluronate. ${ }^{48}$ (d) CD44v6 isoform was the first to be implicated in human carcinoma metastases, conferring metastatic potential to pancreatic carcinoma. ${ }^{14}$ By RT-PCR this form is also found in some breast carcinoma, ${ }^{15,16}$ and in clear cell renal cell carcinoma in $11 / 15$ grade 1 and 10/15 grade 3 cases. $^{19}$ (e) Expression of a v7 isoform on stromal cells allows homing of hematopoietic progenitor cells. $^{20}$ (f) The isoform containing v8-v10 is known as the epithelial form, CD44E. This form is detectable by competitive RT-PCR in bladder cancer tissue and cytologic specimens. ${ }^{5,6,21,22}$ Clear cell renal cell carcinoma expresses this form in a minority of cases: $4 / 15$ grade 1 and 2/15 grade $3 .{ }^{19}$ Expression of this isoform has prognostic value in colon cancer. ${ }^{23}$ (g) In prostatic adenocarcinoma, primers $\mathrm{P} 1$ and $\mathrm{P} 2$, spanning the entire variant region, amplified CD44 isoforms up to $600 \mathrm{bp}$, for which sequencing revealed CD44v7-v10 identity. ${ }^{25}$ By amplifying for CD44v7-v10 in the current study, we obtained a $608 \mathrm{bp}$ fragment, and again sequencing confirmed CD44v7-v10 identity. isoforms shed into the circulation may serve as a diagnostic or prognostic test for malignancy. ${ }^{10}$ An enzyme-linked serum immunoassay (ELISA) may then be developed for sensitive, easier detection of the proteins.

CD44, along with KAI1 and MAP kinase 4, acts as a metastasis suppressor gene in prostate cancer (PC). Both prostate and bladder tumors lose protein antigen expression of CD44s $\mathrm{s}^{11,12}$ and CD44v6 $6^{11,13}$ as the grade of the tumor increases, whereas amplification in CD44v6 is noted with metastatic phenotype of pancreatic cancer ${ }^{14}$ and increasing grade of breast cancer. ${ }^{15,16}$ Inclusion of single or contiguous variant exons has been described by RT-PCR and sequencing in many benign and cancer tissues. ${ }^{5,6,14-23}$ We, ${ }^{11}$ and subsequently others, ${ }^{12,13}$ showed that PC loses immunohistochemical expression of CD44s and some CD44v isoforms. CD44v6 was absent by

\section{cDNA of CD44 Gene}

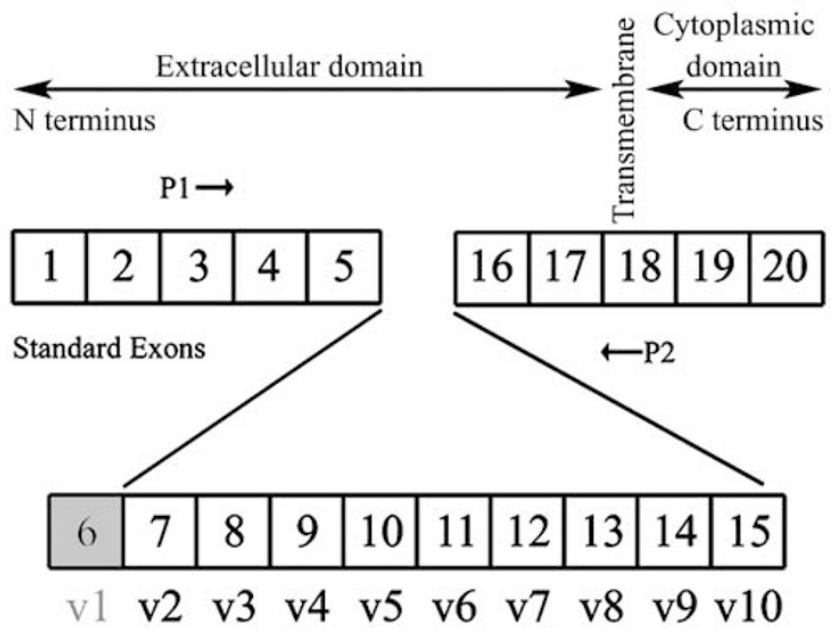

Variant Exons

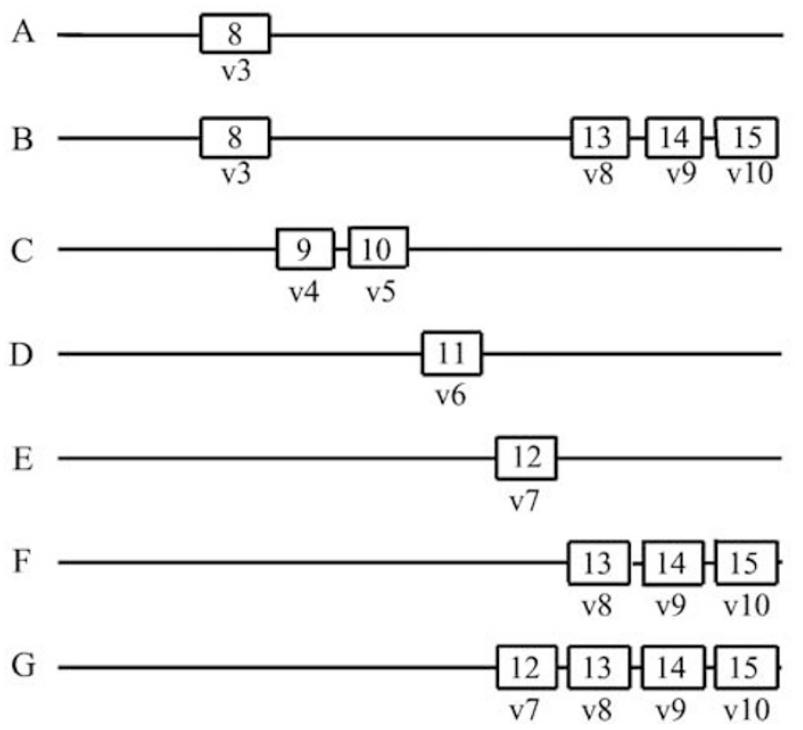


immunohistochemistry in PC of all Gleason grades. Counter to this trend, PC reportedly overexpressed CD44 variant v7 compared with benign prostatic acini. ${ }^{24}$ By Western blotting, we did not find significantly altered CD44 standard and v6 isoform expression in $\mathrm{PC}^{25}$ We did find an increase in proteins that included $\mathrm{v} 7-\mathrm{v} 9$; and amplification using primers $\mathrm{P} 1$ and $\mathrm{P} 2$ spanning the entire v1-v10 variant region (Figure 1) disclosed mRNA whose sequence included combinations of v7-v10 exons. ${ }^{25}$ These findings served as the impetus for the current investigation of their functional significance. Most other cell adhesion molecules are downregulated or unchanged in PC. The exceptions are increased expression of Muc18 (CD146, or MelCAM), ${ }^{26,27}$ N-cadherin and cadherin-11, although expression was consistently seen only in the highest Gleason score cancer, ${ }^{28}$ and $\delta$-catenin. ${ }^{29}$ Muc18 was originally found to be overexpressed on the surface of melanoma cells where it mediates their metastasis. ${ }^{30}$ Others have studied Muc18 in PC in some depth. Expression of Muc18 by prostate cancer cell lines ${ }^{26,27}$ correlated with invasiveness and with in vivo metastasis in nude mice. ${ }^{26}$ Also, Muc18 immunohistochemical expression was increased in prostate cancer acini and their precursor lesion, prostatic intraepithelial neoplasia (PIN), in 37 cases. $^{27}$ Thus, we chose to study the effect of expression and silencing of Muc18.

CD44v9 is the longest sequence within the CD44v7-v10 region. Since the v7-v10 exons were consistently expressed together, we chose to induce CD44v9 silencing in the current study in order to discover the functional significance of CD44v7-v10 expression. The relative functional significance of CD44v9 and Muc18 in characterized prostate cancer cell lines was compared in Matrigel invasion assays. Matrigel experiments will serve as a prelude to animal studies and clinical trials. If abrogation of overexpression of these cell adhesion molecules impairs cancer cell survival or metastasis, gene therapy may be targeted to them. A component of the current study was to determine whether $\mathrm{G}_{\mathrm{s}} \alpha$ cells, PC cells which have a constitutively active $\mathrm{G}_{\mathrm{s}} \alpha^{31}$ and demonstrate increased invasiveness, ${ }^{32}$ also overexpress CD44v9 or Muc18. Finally, we acquired a CD44v10 antibody and performed immunostaining on a prostate tissue microarray in order to determine whether CD44v10 is increased in PC at the protein level along with CD44v7-9, as we showed previously. ${ }^{25}$

\section{Materials and methods}

\section{RNA Extraction from Prostatic Tissue}

Tissue was harvested from prostatectomy, enucleation or transurethral resection specimens, and in two cases, pelvic lymph nodes with metastatic tumor, within $20 \mathrm{~min}$ of surgery, with patient informed consent. Tissue was snap-frozen in liquid nitrogen and stored at $-70^{\circ} \mathrm{C}$. Frozen sections were performed on the tissue before use to verify that it either contained $>50 \%$ tumor or was free of tumor.

Total RNA was isolated from the prostate tissues using Trizol (Invitrogen, Carlsbad, CA, USA) as described by the manufacturer with some modifications. Briefly, $100 \mu \mathrm{g}$ of frozen prostate tissue was ground on dry ice by cold mortar and pestle, and the powder was transferred directly into $2 \mathrm{ml}$ of RTL lysis buffer (Qiagen, Valencia, CA, USA) $+20 \mu$ l of 2-mercaptoethanol (Sigma) and mixed by gentle inversion. To every $500 \mu \mathrm{l}$ of this mixture, $1 \mathrm{ml}$ of Trizol was added, mixed by inversion and incubated for $5 \mathrm{~min}$ at room temperature. This was followed by addition of $200 \mu \mathrm{l}$ of chloroform, mixed again by inversion and incubated for $10 \mathrm{~min}$ at room temperature. The mixture was centrifuged at $14000 \mathrm{rpm}$ for $10 \mathrm{~min}$ at $4^{\circ} \mathrm{C}$ in a bench centrifuge (Sorvall RMC 14). Total RNA was further purified by isopropanol precipitation. The isolated total RNA was dissolved in DEPC-treated water and quantified. Laser capture microdissection was performed in two lymph node metastasis specimens, and total RNA was isolated using PicoPure RNA Isolation Kit according to the manufacturer's protocol (Arcturus, Mountain View, CA, USA). The quality of RNA was verified by loading $6 \mu \mathrm{g}$ of total RNA in separate wells, electrophoresis on $1 \%$ formaldehyde-agarose gel, and visualizing bands by ethidium bromide staining and UV transillumination.

\section{First-strand cDNA Synthesis and RT-PCR for CD44v7-v10}

For first-strand complementary DNA (cDNA) synthesis, $1 \mu \mathrm{g}$ of total RNA was mixed with random hexamers (Invitrogen) to a final concentration of $50 \mathrm{ng}$ per reaction and DEPC-treated water was used to bring the volume to $10 \mu \mathrm{l}$. The mixture was heated to $70^{\circ} \mathrm{C}$ for $10 \mathrm{~min}$ and incubated on ice for $10 \mathrm{~min}$. Reverse transcription was started by adding $10 \mu \mathrm{l}$ of a master mix ( $4 \mu \mathrm{l}$ of $5 \times$ buffer, $2 \mu \mathrm{l}$ of $100 \mathrm{mM}$ DTT, $1 \mu \mathrm{l}$ of dNTPs, $1 \mu \mathrm{l}$ (200 U) of SuperScript ${ }^{\mathrm{TM}}$ II RNase $^{\mathrm{H}}$ Reverse Transcriptase (Invitrogen) and DEPC-treated water to a total volume of $10 \mu \mathrm{l}$ ). A master mix of the above was prepared for 12 reactions and to each master mix $1 \mu \mathrm{l}$ of RNAse Out (Invitrogen) was added. First-strand cDNA synthesis was carried out at $25^{\circ} \mathrm{C}$ for $10 \mathrm{~min}$, followed by $42^{\circ} \mathrm{C}$ for $45 \mathrm{~min}$, and the reaction was stopped by heating at $70^{\circ} \mathrm{C}$ for $3 \mathrm{~min}$. The first-strand cDNAs were used as templates in PCR reactions.

For PCR amplification, $5 \mu \mathrm{l}$ of the first-strand cDNA, $2.5 \mu \mathrm{l}$ of $10 \mu \mathrm{M}$ stock of the E3/P4 primer $\operatorname{set}^{33}$ and $2.5 \mu \mathrm{l}$ of Taq polymerase (diluted 1:10) were added to $37.5 \mu \mathrm{l}$ of master mix to make a $50 \mu \mathrm{l}$ reaction volume. Master mix consisted of $1 \times$ PCR buffer, $1.5 \mathrm{mM} \mathrm{MgCl}_{2}$ and $200 \mu \mathrm{M}$ dNTPs. The PCR 
conditions were as follows: $94^{\circ} \mathrm{C}$ for $5 \mathrm{~min} ; 5$ cycles at $94^{\circ} \mathrm{C}$ for $1 \mathrm{~min}, 50^{\circ} \mathrm{C}$ for $1 \mathrm{~min}$, and $72^{\circ} \mathrm{C}$ for $3 \mathrm{~min}$; 30 cycles at $94^{\circ} \mathrm{C}$ for $1 \mathrm{~min}, 60^{\circ} \mathrm{C}$ for $1 \mathrm{~min}$, and $72^{\circ} \mathrm{C}$ for $3 \mathrm{~min}$; and a final extension of $72^{\circ} \mathrm{C}$ for $10 \mathrm{~min}$. An amount of $5 \mu \mathrm{l}$ of PCR product was loaded on a $0.8 \%$ agarose gel and electrophoresed at $100 \mathrm{~V}$ for $1 \mathrm{~h}$ and visualized by ethidium bromide staining and UV transillumination. The bands of interest were excised and the DNA extracted out of the gel using the StrataPrep DNA Gel Extraction Kit (Stratagene, La Jolla, CA, USA). The purified DNA was cloned into TOPO (TOPO TA cloning kit for sequencing, Invitogen) and resulting plasmids were sequenced by the University of Florida DNA Sequencing Core. Sequences were compared to published ones ${ }^{34}$ using JellyFish (LabVelocity, Burlingame, CA, USA).

\section{Immunohistochemistry for CD44v10}

CD44v10 reactivity in 55 malignant and benign prostate cores and 18 benign tissues other than prostate were assessed using Tissue Array Research Program tissue microarray slides (National Cancer Institute, Bethesda, MD, USA). Tissue sections were deparaffinized in xylene and alcohols and soaked $30 \mathrm{~min}$ in Tris-buffered saline, $\mathrm{pH}=7.5$ with $0.1 \%$ Tween-20 (TBST). Slides were subject to steam heat antigen retrieval in citrate buffer, $\mathrm{pH}=6$ for $2 \times 30 \mathrm{~min}$. Slides were quenched in $3 \%$ $\mathrm{H}_{2} \mathrm{O}_{2}$ in methanol for $10 \mathrm{~min}$ and rinsed well in distilled water, then in TBST. An 'Inhibitor solution' (Ventana) was applied for $4 \mathrm{~min}$ followed by blocking antibodies for $10 \mathrm{~min}(20 \%$ normal swine serum in Tris-HCl, $\mathrm{pH}$ 7.6). A 1:1000 dilution of monoclonal anti-CD44v10 (Biosource, Camarillo, CA, USA) was applied at room temperature, overnight. Its specificity was confirmed by Western blot using normal lymph node as a positive control. ${ }^{5}$ Biotin block (Ventana) was applied 3 min. A secondary antibody (Dako LSAB Kit mouse/goat/ rabbit) was applied for $25 \mathrm{~min}$. Slides were rinsed in TBST, covered with avidin-biotin complex $25 \mathrm{~min}$, and rinsed in TBST. Diaminobenzidine served as the chromogen, and slides were counter- stained with hematoxylin. The negative control consisted of application of nonimmune whole rabbit serum at 1:300 dilution. Number of benign and tumor tissues staining was compared by $\chi^{2}$-test. The two-tailed two-sample sign test was used to assess differences between staining of paired benign and cancer tissue.

\section{Cell Culture}

PC3M cells were purchased (American Type Culture Collection, Manassas, VA, USA) and incubated in RPMI 1640 with L-glutamine, 10\% fetal calf serum, and antibiotics at $37^{\circ} \mathrm{C}$ in a $5 \% \mathrm{CO}_{2}$ incubator. $\mathrm{G}_{\mathrm{s}} \alpha$ prostate cancer cells were maintained in complete medium (RPMI 1640 supplemented with L-glutamine, $5 \%$ fetal calf serum, $12 \%$ horse serum, $50 \mathrm{U} / \mathrm{ml}$ penicillin, $50 \mu \mathrm{g} / \mathrm{ml}$ streptomycin, $20 \mu \mathrm{g} / \mathrm{ml}$ amphotericin).

\section{RNA Interference: Cloning of two-DNA Nucleotide Fragments, and Transfection for Synthesis of siRNA}

We used RNAi to study the function of CD44 and Muc18 genes in prostate cancer cells. The sequence of CD44v9 was found in GenBank and in Screaton et al. ${ }^{34}$ The sequence of Muc18 was likewise found in published data. ${ }^{25}$ Our strategy was to design and synthesize two pairs of $21 \mathrm{bp}$ oligonucleotides for each molecule (two sense and two antisense) based on 21-nucleotide DNA fragments of each molecule (Figure 2). The first $21 \mathrm{bp}$ oligonucleotide, 1a, started in an area with 3G's but we used only GG in the oligonucleotide because another $\mathrm{G}$ is provided by the vector (after Apa I digestion and Klenow treatment). The GGG serves as the initiation site for the transcription of RNA Polymerase III (Pol III). The complementary strand of oligonucleotide 1a was synthesized as oligonucleotide $1 \mathrm{~b}$. To the upper strand of the second pair of $21 \mathrm{bp}$ oligonucleotides, 2a, after CCC, we added TTTTT to give a Pol III transcription termination site. This was followed by an EcoRI site. The complementary strand of $2 \mathrm{a}$ was synthesized as oligonucleotide $2 \mathrm{~b}$. We used Hind III to

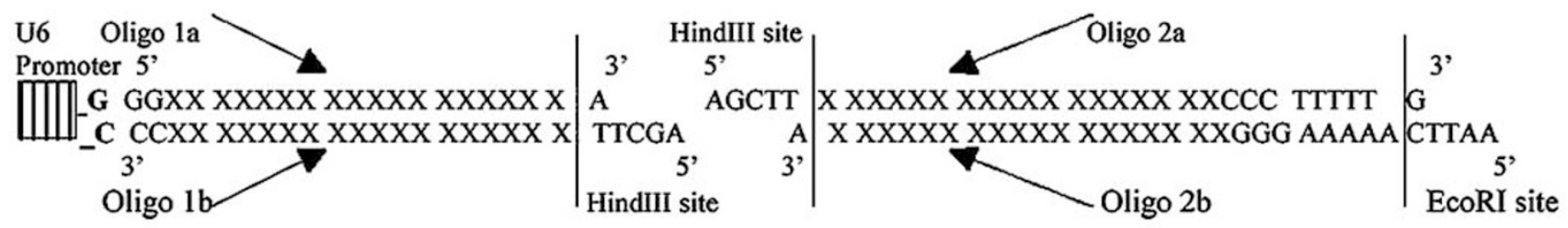

\section{Transcripted SiRNA:}

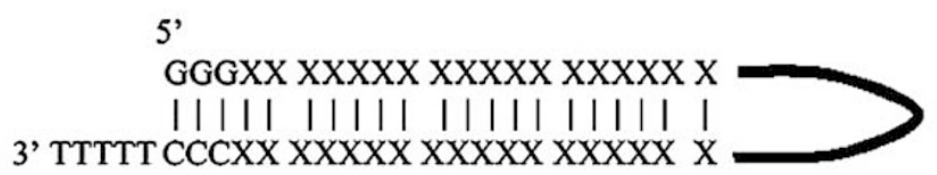

Figure 2 The strategy for production of double-stranded DNA to cause RNAi in tumor cells. 
make a connection between the two pairs of oligonucleotides. The complementary oligonucleotides were annealed by mixing (from $250 \mathrm{pmol} / \mu \mathrm{l}$ stock) $10 \mu \mathrm{l}$ of one oligonucleotide with $10 \mu \mathrm{l}$ of the second oligonucleotide in $180 \mu \mathrm{l}$ of water, boiling the $200 \mu \mathrm{l}$ mixture in a $700 \mathrm{ml}$ water bath for $5 \mathrm{~min}$ and gradual cooling of the water bath with the $200 \mu \mathrm{l}$ mixture for $1 \mathrm{~h}$ followed by incubation on ice for $10 \mathrm{~min}$. Using a two-step cloning strategy, the two pairs of the 21-DNA nucleotide fragments were arranged head to head and sandwiched with a loop of six nucleotides (Hind III site) into plasmid vector U6pBS. Once the two pairs of the 21-DNA nucleotide were cloned in vector U6pBS, clean endotoxin-free plasmids were prepared using the Endo Free Plasmid Maxi Kit (Qiagen) and the plasmids were then used in transfection experiments. The goal was to generate short hairpin RNAs in transfected cells, to suppress specific CD44v9 or Muc18 gene activity as described. ${ }^{35}$

Transfection of cells with vector U6pBS having RNAi constructs was optimized using the lipid agent Metafectene (Biontex, Munich, Germany). In brief, cells were plated at a density of $5 \times 10^{5}$ cells per well in $2 \mathrm{ml}$ of RPMI medium with serum and antibiotics in a 6-well plate. Cells were then transfected $24 \mathrm{~h}$ later with vector U6pBS containing RNAi construct:Metafectene complexes. To formulate RNAi construct:lipofection complexes, two tubes were filled with $100 \mu \mathrm{l}$ of RPMI without serum or antibiotics. To one tube, $10 \mu \mathrm{l}(10 \mu \mathrm{g})$ of PCI-neoGFP plasmid (which produces green fluorescent protein (GFP)) as a reporter was added, followed by $10 \mu \mathrm{l}(4 \mu \mathrm{g})$ of RNAi construct (for CD44v9 or Muc18). To the second tube, $10 \mu \mathrm{l}$ of Metafectene were added. The contents of the two tubes were mixed well, then allowed to stand 25 min to allow formation of lipofection agent:DNA complexes for transfection. The incubated complex was added dropwise to the cells in each well, from which the serum-containing medium had been removed. An amount of $4 \mu \mathrm{g}$ of GFP was cotransfected to monitor the extent of transfection. Transfection in serum-free medium proceeded for $6 \mathrm{~h}$. Others have found a 3-4 day interval of further incubation optimal in order for depletion of previously synthesized protein. ${ }^{36}$ We tried post-transfection incubations ranging from 1-6 days, and optimized the interval for abrogation of protein expression by Western blot at $90 \mathrm{~h}$, in serum-containing medium.

In one experiment, cells were successfully sorted by FACS into GFP-positive and GFP-negative cell groups using a FACSVantage SE flow cytometer (BD Biosciences, San Diego, CA, USA). Portions of these cell populations were analyzed separately by Western blotting and used in the Matrigel invasion assay as above. Differences in percent cell invasion (compared to control insert) of the GFP-positive and -negative populations were analyzed by the $\chi^{2}$-test.

\section{SDS-Polyacrylamide Gel Electrophoresis and Western blot Analysis for CD44v9}

SDS-PAGE was performed according to the method of Laemmli $^{37}$ using $12 \%$ polyacrylamide gels. A pellet from centrifuged cultured cells was lysed in RIPA lysis buffer (Upstate Biologicals, Lake Placid, NY, USA) plus the protease inhibitors $2 \mu \mathrm{g} / \mathrm{ml}$ Pepstatin, $1.5 \mu \mathrm{g} / \mathrm{ml}$ Leupeptin and $1 \mathrm{mM}$ PMSF. The cell lysate was treated with an equal volume of $2 \%$ SDS and the protein concentration was estimated by Lowry method.

One part of $5 \times$ sample buffer (formulated as described by BIO-RAD) was added to four parts of the solubilized proteins. An amount of $25 \mu \mathrm{g}$ of sample/lane was prepared. The proteins were then denatured for $5 \mathrm{~min}$ in $100^{\circ} \mathrm{C}$ boiling water bath and loaded into wells of a $4 \%$ stacking gel. A measure of $5 \mu \mathrm{l}$ of Rainbow protein marker (RPN 756 Amersham Pharmacia, Piscataway, NJ, USA) was also loaded on each gel. After 2-h electrophoresis, the protein was transferred to nitrocellulose (Trans-Blot Transfer Medium, BIO-RAD). For Muc18 protein, a primary goat polyclonal IgG antibody (Santa Cruz Biotechnology, Santa Cruz, CA, USA) was hybridized at 1:1000 dilution. Bovine anti-goat IgG labeled with horseradish peroxidase (Santa Cruz) was used as a secondary antibody at 1:10 000 dilution. To assess CD44v9, the membrane was reacted with supernatant from the hybridoma cell line HB-258 (ATCC, Manassas, VA, USA) which produces antibody against CD44v9, and this was used neat. Goat antimouse IgG labeled with horseradish peroxidase (Pierce, Rockford, IL, USA) was used as a secondary antibody at 1:50000 dilution. Reactivity was detected using a chemiluminescent system (SuperSignal West Pico Substrate, Pierce). Each experimental run was conducted twice.

\section{Invasion Study}

The experiment was performed in six-well Matrigel two-tier invasion chambers (Collaborative Biomedical Products, Bedford, MA, USA), using a protocol similar to that used successfully by others. ${ }^{32}$ Prostate cancer cells $\left(2.5 \times 10^{5}\right.$ cells per well expressing hairpin double-stranded CD44v interfering RNA or controls) were seeded in the upper insert in a serumfree basal medium (RPMI 1640 medium containing $0.1 \% \mathrm{BSA}, 150 \mathrm{mg} / \mathrm{ml}$ of $\mathrm{G} 418,4 \mathrm{mM}$ L-glutamine, $100 \mu \mathrm{g} / \mathrm{ml}$ penicillin $\mathrm{G}$ and $100 \mu \mathrm{g} / \mathrm{ml}$ streptomycin). The lower chamber contained chemoattractant medium consisting of $70 \%$ complete medium, $10 \%$ fetal bovine serum, and $20 \%$ conditioned medium obtained from subconfluent cultures. The incubations were carried out for $36 \mathrm{~h}$. After this period, upper inserts were removed, and residual cells were removed from the upper Matrigel surface using cotton swabs. The invasive cells would penetrate through the Matrigel layer and would be on the outside bottom of the upper insert. While the 
membranes were still wet in culture dishes, the GFP-positive cells on the entire membrane were counted under fluorescent illumination. Gels were fixed, stained using Diff Quik staining (Dade Diagnostic, Aguar, PR, USA), and mounted on glass slides. The total number of cells on the entire gel was counted. The data from invasion assay were corrected for cell growth during experimental periods as follows: the experimental cells were plated at a density of $10^{5}$ cells per well in six-well control inserts in chemoattractant medium and increase in cell number were determined after $48 \mathrm{~h}$. Four experiments were carried out with PC3M cells and five with $\mathrm{G}_{\mathrm{s}} \alpha$ cells. The results were expressed as mean \pm standard deviation.

The Percent Invasion is defined as

$100 \times($ Number of cells invading through entire Matrigel insert membrane)/Number of cells invading through entire control insert membrane.

The Invasion Index is defined as

$100 \times$ (Percent Invasion of treated cells) $/$ (Percent Invasion of untreated cells).

Significance of differences in Percent Invasion according to treatment (or transfection of Metafectene vehicle alone) were assessed by Student's $t$-test.

\section{Results}

\section{RT-PCR}

After RT-PCR using the E3/P4 primer set, purification, and cloning into TOPO vector, a $608 \mathrm{bp}$ band was amplified in nine of 10 malignant, but no benign, prostate tissues tested. A $638 \mathrm{bp}$ band was obtained in one primary tumor and two lymph node metastases (Figure 3a) with ribosomal 18S RNA serving as the normalizer in each trial (Figure 3b). Sequencing of the $608 \mathrm{bp}$ bands showed that they contained the published human CD44v7-v10 region as well as the preceding and following standard exons (Figure 3c, d). However, the $638 \mathrm{bp}$ bands represented the upstream primer binding to part of the exon for CD44v6, with amplification continuing through v10 as with the $608 \mathrm{bp}$ bands. Benign and tumor specimens also yielded a $212 \mathrm{bp}$ band. Sequencing of this band revealed that it represented nonspecific binding of primer E3 to exon 5, with inclusion of CD44v10, and distal standard exons (Figure 3e). The faint $100 \mathrm{bp}$ bands are primer-dimers.

\section{Immunostaining}

Immunoreactivity (Figure 4a) was present at $1+/$ $3+$ in benign prostate in $10 / 37(27 \%)$ of samples, and at a mean $1.6+/ 3+$ in $49 / 55(89 \%)$ of tumor samples $(P=0.001)$. Reactivity for CD44v10 was cytoplasmic, with no nuclear staining and minimal to absent stromal background (Figure 4b, c). In 23 of 27 cases in which paired benign and tumor tissue cores were provided and were evaluable, tumor showed increased CD44v10 expression $(P=0.01)$.
No significant difference was noted in v10 expression between lower grade (Gleason $\leq 6)$ and higher grade (Gleason $\geq 7$ ) tumors ( $\chi^{2}$-test).

\section{RNA Interference}

Either parental PC3M or $\mathrm{G}_{s} \alpha$ prostate cancer cells were transfected with an expression vector that caused RNA interference (RNAi). Others have documented that the RNAi effect takes up to 4 days after transfection to become maximal and may persist up to 6 days post-transfection. ${ }^{36}$ We also noted no change in protein expression by Western blot after $24-48 \mathrm{~h}$; therefore, we waited $90 \mathrm{~h}$ before performing the Matrigel invasion assay.

Two observations emerged. Untreated cell lines, firstly, differed in CD44v9 expression, with $\mathrm{G}_{\mathrm{s}} \alpha$ cells tending toward stronger expression than PC3M cells. Second, CD44v9-containing protein expression was decreased after RNAi for CD44v9, by Western blot analysis (Figure 5a-d). Likewise, Muc18 expression was decreased after RNAi for Muc 18 (Figure 5c, d). After FACS cell sorting, for the $G_{s} \alpha$ cells, transfection of GFP plasmid alone yielded $46.9 \%$ GFP-positive cells; cotransfection with CD44v9 expression vector yielded $45.9 \%$ GFP-positive cells, and cotransfection of Muc18 expression vector yielded $34.1 \%$ GFP-positive cells. PC3 cell viability after FACS, however, was insufficient for further study to compare the GFP-positive and -negative cells. Counts of live and dead cells showed similar survival rates of $54-63 \%$ for RNAitreated PC3M cells and $73-76 \%$ for the $\mathrm{G}_{\mathrm{s}} \alpha$ cells. The GFP-positive cell population was shown by Western blot to have undergone successful RNA interference for the desired gene product (Figure 5c, d). The percent of invaded cells that had been counted on the membrane as GFP-positive was $12.5-38.7 \%$ for the PC3M cells and $5.0-11.7 \%$ for the $\mathrm{G}_{\mathrm{s}} \alpha$ cells, indicating that most of the cells that had invaded were untransfected.

\section{Matrigel Invasion Study}

After PC3M and $G_{s} \alpha$ cells were transfected, we studied their invasion into Matrigel, a basement membrane-like substance (Figure 6a-d). In four experiments with the PC3M cells and five with the $\mathrm{G}_{\mathrm{s}} \alpha$ cells, markedly fewer cells receiving RNAi for CD44v9, or for CD44v9 plus Muc18, were able to invade through the membrane compared to the cells receiving no RNAi. Cells receiving RNAi for only Muc18 showed slightly inhibited invasion. The bar graphs (Figure 7a) show mean differences in Invasion Index (see Materials and methods) depending on transfection treatment of the cells. With CD44v9 RNAi, PC3M cells had an Invasion Index of $21.61 \% \pm 7.03 \%$ of the invasive potential of control cells transfected with vehicle alone $(P<0.001)$. Under this condition, the percent of the $G_{s} \alpha$ cells 


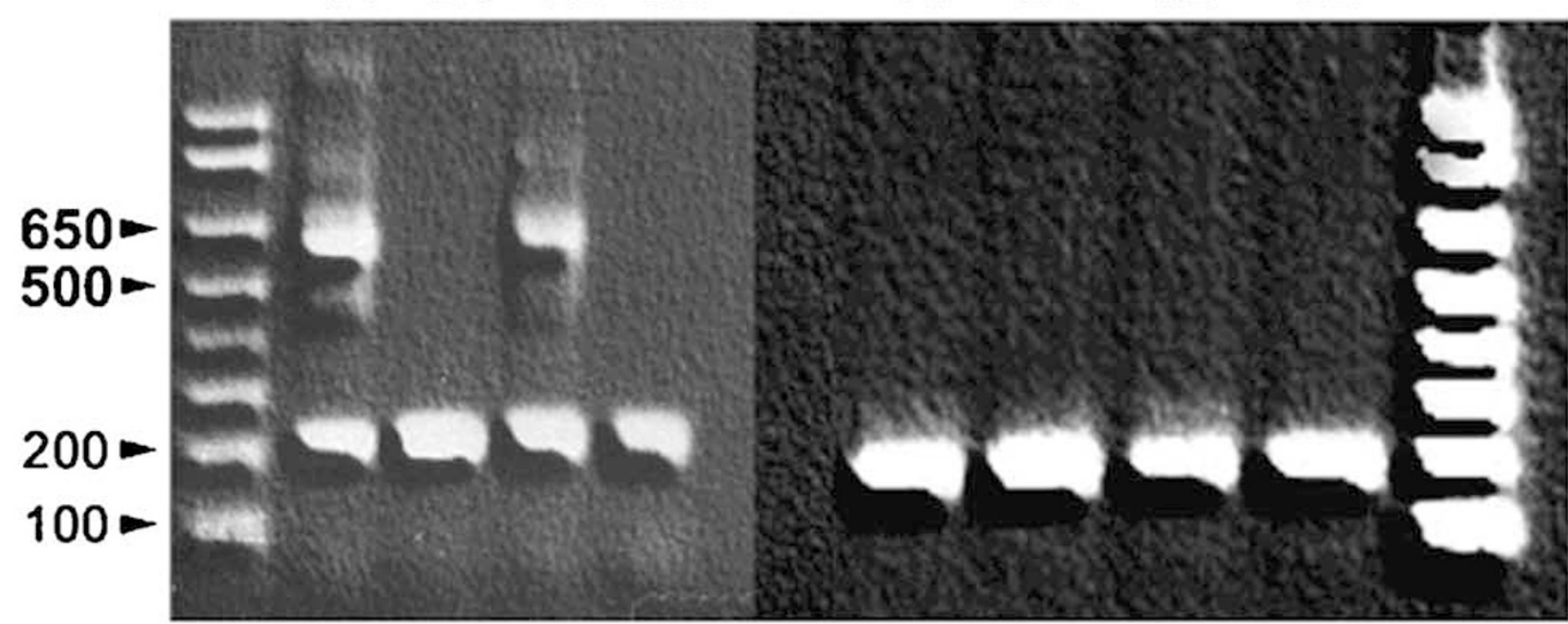

c 608 base pair amplified band in T1 originated from Gleason 4+3=7 tumor. Cloning of this purified PCR product into TOPO vector and sequencing disclosed total correspondence to the published CD44 v7-10 transcript, corresponding to variant exons 12-15 (28, 32). Primers are represented by boxes.

E3 upstream primer AGCCCAGAGGACAGTTCCTGG

P4 downstream primer TTCCAGAATGGCTGATCATCTTGGCATC

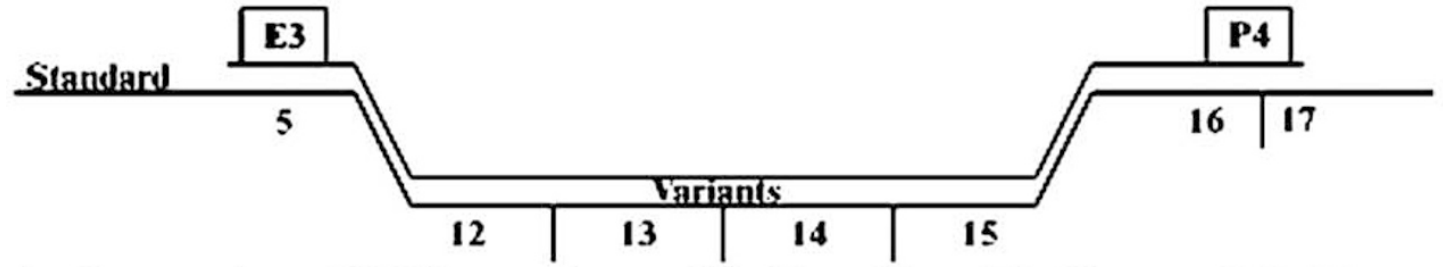

d Sequencing of 638 base pair amplified band from T2, Gleason 3+3=6 tumor and metastatic tumors, disclosed partial inclusion of exon 11, CD44v6, in addition to CD44v7-10. Primers are represented by boxes.

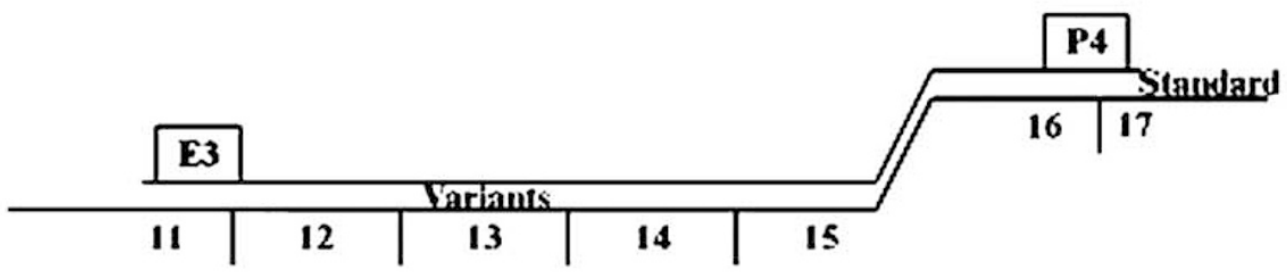

e 212 base pair band seen in all samples. Part of primer E3 bound nonspecifically to exon 5 and amplified CD44 standard exons 5 and 15, including the variant exon 15 (v10). Primers are represented by boxes.

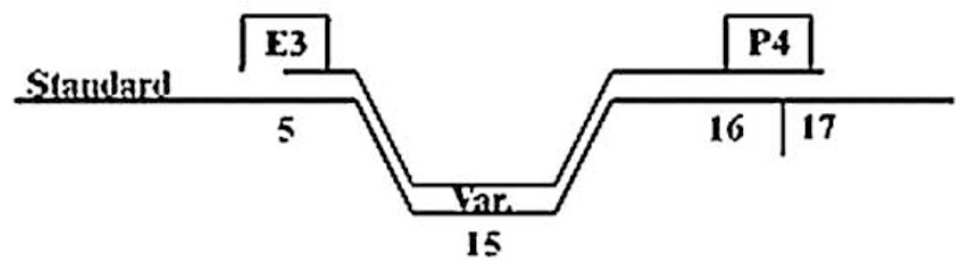




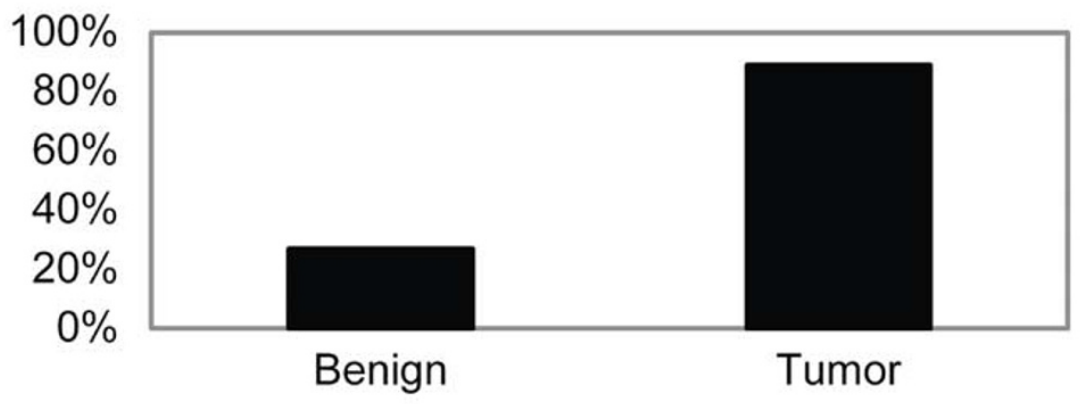

$\%$ of Cases CD44v10-Immunoreactive
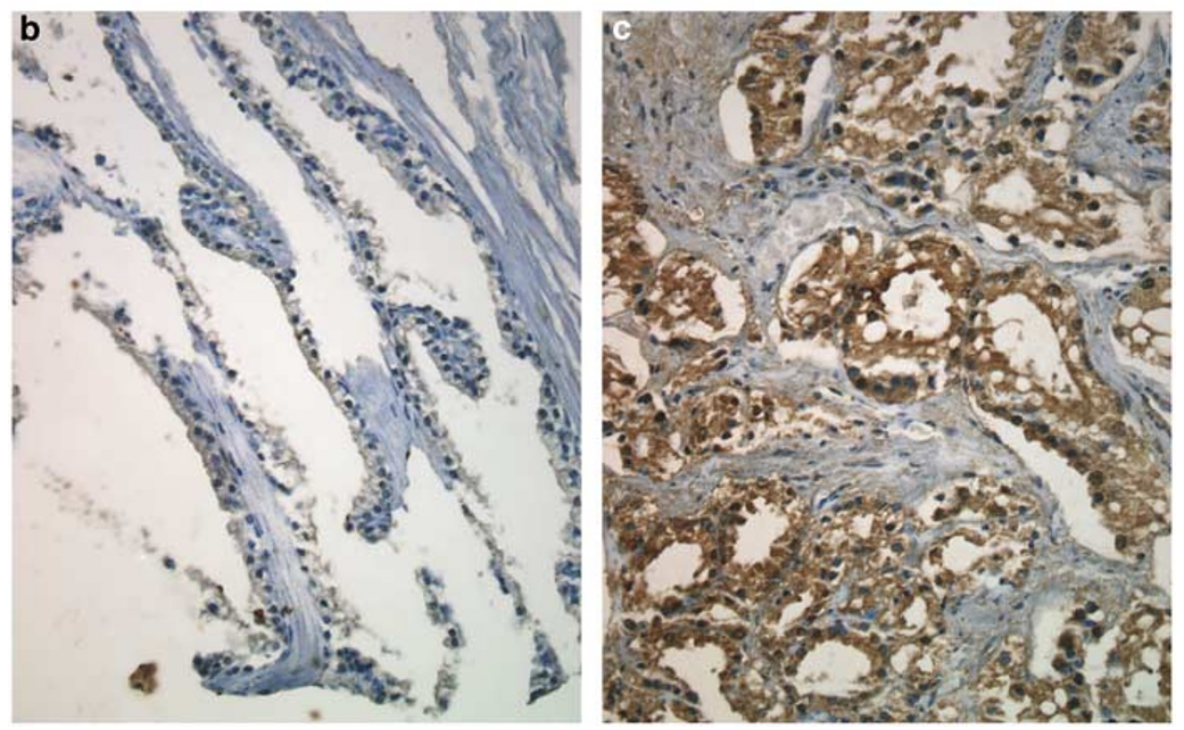

Figure 4 (a) Immunostaining reveals increased reactivity for CD44v10 in 55 prostatic tumors compared to benign prostate. More tumors were reactive $(89 \%$ vs $27 \%, P=0.001)$. Benign prostate $(\mathbf{b})$ had weaker mean reactivity of $1.0+$ compared to tumor $(\mathbf{c})$ at $1.6+$. Reactivity was more intense in tumor in 23 cases in which paired tumor and benign tissue were available $(P=0.01)$.

invading was $31.28 \pm 18.25 \%(P<0.001)$. Cells undergoing Muc18 inhibition had a higher Invasion Index of $76.9 \pm 13.5 \%$ for the PC3M cells $(P<0.05)$ and $84.8 \pm 29.9 \%$ for the $G_{s} \alpha$ cells $v s$ controls $(P=0.18)$, implying a stronger role for CD44v9 than Muc18 expression in allowing invasion. RNAi performed for both CD44v9 and Muc18 in both cell lines gave similar results to RNAi for CD44v9 only (both $P<0.001$ ).

Matrigel invasion assay performed after FACS cell sorting of $\mathrm{G}_{\mathrm{s}} \alpha$ cells according to GFP positivity revealed differences in number of invaded GFPpositive and GFP-negative cells (Figure 7b). Cells after CD44v9 interference had 11\% invasion of GFPpositive cells vs 54\% invasion of GFP-negative cells $(P<0.005)$. Cells after Muc18 interference had 59\% invasion of GFP-positive cells and $81 \%$ invasion of GFP-negative cells $(P<0.025)$.

\section{Discussion}

Our study produced these main findings: (1) confirmation that prostate cancer (PC) overexpresses CD44v7-v10 by RT-PCR for that region; (2) demonstration that RNA interference with this variant region can decrease invasiveness of two PC cell

Figure 3 (a) RT-PCR of two frozen section-confirmed prostatic tumor tissues, T1 and T2 (lanes 1 and 3, Gleason scores $4+3=7$ and $3+3=6$ ), discloses amplified products at 608 and $638 \mathrm{bp}$. Faint, longer bands ranging to the upper $800 \mathrm{~s}$ were recognized in tumor and may represent inclusion of more introns or exons. Two matched benign tissues, B1 and B2, from the same prostatectomy specimens did not show these bands (lanes 2 and 4). The 608 or $638 \mathrm{bp}$ product were amplifiable in 11 malignant, but no benign, prostatic tissues. Cloning of the purified $608 \mathrm{bp}$ DNA into TOPO vector and sequencing was performed. (The faint $100 \mathrm{bp}$ bands in all lanes are primerdimers.) (b) As a control, primers for $18 \mathrm{~S}$ ribosomal RNA amplified the same samples similarly. (c-e) contained in text. 

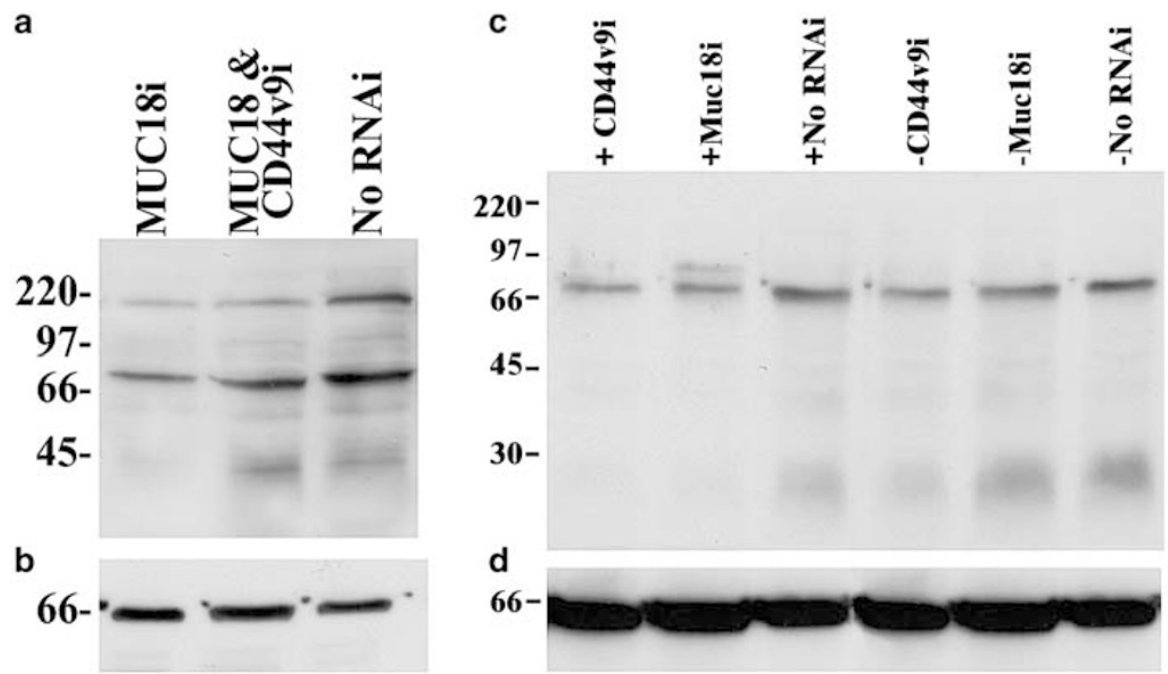

Figure 5 (a) Western blot analysis in which PC3M prostate cells show decreased Muc18 expression after RNAi for only Muc18 (lane 1 ) or Muc18 and CD44v9 (lane 2) compared to no RNAi (lane 3). (b) Three bands for $\alpha$-tubulin, situated at $66 \mathrm{kDa}$, resulting from rehybridization of this membrane. (c) Western blot analysis of CD44v9 protein expression in flow cytometric-sorted $\mathrm{G}_{\mathrm{s}} \alpha$ prostate cells after expression vector lipofection for RNA interference (RNAi). An amount of $50 \mu \mathrm{g}$ of protein was loaded per lane. In GFP-positive cells (lanes 1-3), successful RNAi is confirmed by the decreased CD44v9 protein product (lane 1), compared with Muc18 RNAi (lane 2) or Metafectene with no RNAi (lane 3). In the GFP-negative cells (lanes 4-6), slightly less protein product is observed in cells that underwent CD44v9 RNAi (lane 4). This suggests that some GFP-negative cells were positive for the CD44v9 construct, despite using $10 \mu \mathrm{g}$ of GFP DNA but only $4 \mu \mathrm{g}$ of CD44v9 interference construct DNA. (d) Six bands for $\alpha$-tubulin, situated at $66 \mathrm{kDa}$, are of uniform intensity, verifying equal protein loading.

lines; and (3) preliminary evidence that amplification of this CD44v7-v10 region is linked to constitutive activation of G-proteins.

Our recent publication ${ }^{25}$ presented RT-PCR amplification data in PC using primers that flanked the entire CD44 variant region and included some of a preceding and a following standard exon. When the RT-PCR products were separated by electrophoresis, Southern blotted and probed for a specific exon, benign prostate revealed a single $500 \mathrm{bp}$ band. Tumor tissue uniquely featured $600-1000 \mathrm{bp}$ bands whose sequencing revealed various combinations of CD44 standard exons $3-5,16$, or 17 plus v7-v10, v8v10, or v10 cDNA. In situ hybridization for the CD44v7 variant supported its overexpression in PC. This confirmed two prior reports using RT-PCR for CD44. One found abnormal splice variants in tissue of two of three patients with $\mathrm{PC} ; 3^{38}$ the second ${ }^{2}$ looked at two PC cell lines and identified additions to exons 11 and 12 (the latter being responsible for v7 variant). We narrowed the scope of the amplifiable region in the current study by using a primer set for the CD44v7-v10 region. This yielded a $608 \mathrm{bp}$ product, for which sequencing confirmed its specific identity. The discovery of $638 \mathrm{bp}$ bands including CD44v6 in primary prostate tumor as well as laser capture-microdissected nodal metastases stands in contrast to the absence of CD44v6 by immunostaining ${ }^{11,13}$ and Western blotting ${ }^{25}$ in both primary tumor and metastases. Either the messenger RNA containing CD44v6 is not translated or it is translated into an aberrant protein that is not immunodetectable. There were faint, longer bands above $800 \mathrm{bp}$, as seen previously. These longer bands may represent inclusion of other introns or exons in some transcripts.

The consistent high expression of CD44v7-v10 in PC provided the impetus for our investigation of its functional significance. Recently, RNA interference (RNAi) has emerged as a powerful technique for studying gene function in a variety of organisms, ${ }^{39,40}$ including mammalian cells. ${ }^{35}$ We chose to use RNAi for a portion of the CD44v9 exon, since v7-v10 exons are usually expressed together, ${ }^{25}$ as well as for another cell adhesion protein, Muc18. According to previous work, expression of Muc18 by prostate cancer cell lines ${ }^{26,27}$ correlates with invasiveness and with in vivo metastasis in nude mice. ${ }^{26}$ Muc18 interference gave a modest but significant decrease in invasion, consistent with this work. However, CD44v9 expression proved to be comparatively more important in causing invasion. These results provided empirical evidence that abrogation of CD44v9 expression decreases invasiveness. More direct confirmation was obtained by cotransfection of a plasmid containing a GFP reporter dye. Limitations of our study were that the transfection efficiency, judging by GFP positivity, was $34-47 \%$ and that suppression of CD44v9 or Muc18 protein by Western blot analysis was not complete (Figure 5a, c). However, invaded cells that were GFPpositive were $12.5-38.7 \%$ for the PC3M cells and $5.0-11.7 \%$ for the $G_{s} \alpha$ cells, suggesting that with $34-$ $47 \%$ transfection efficiency, the majority of invaded cells were GFP-negative. Furthermore, after cell sorting, the GFP-positive cells, whether undergoing 

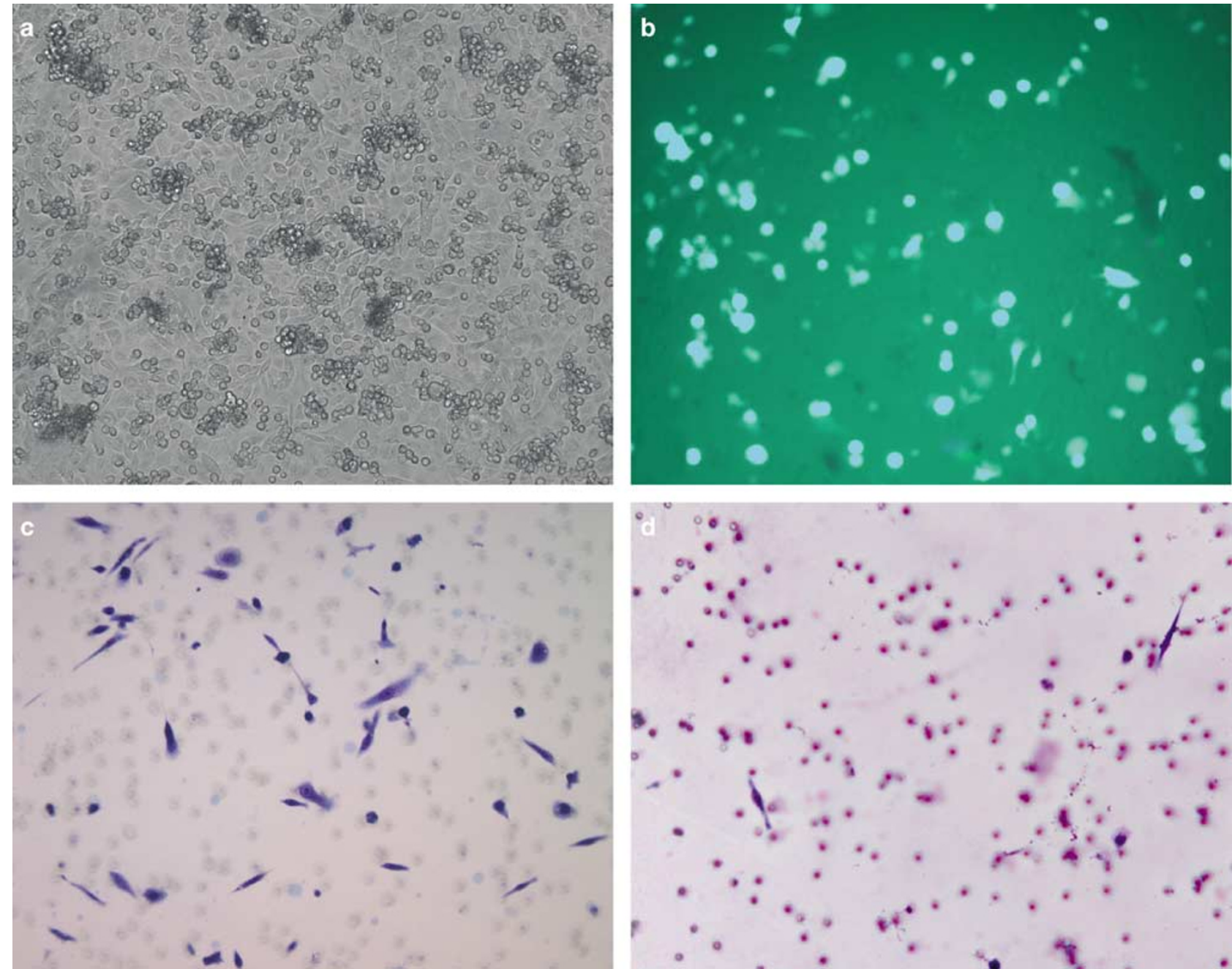

Figure 6 Photomicrographs. (a) Prostate $\mathrm{G}_{\mathrm{s}} \alpha$ cells are confluent after transfection of GFP and vector to cause RNAi for CD44v9 ( $\times 100$ ). (b) In this same field, $G_{s} \alpha$ cells show frequent uptake of GFP, corresponding by flow cytometric sorting to $46 \%$ of cells. (c) After swabbing the upper surface and staining the Matrigel, untreated $\mathrm{G}_{s} \alpha$ cells frequently invaded to the lower surface, representing $97 \%$ as many cells as invaded the control insert in this experiment. Pores of membrane with some dye uptake are in a different focal plane $(\times 200)$. $(\mathbf{d})$ GFPpositive cells were placed on the Matrigel membrane. After treatment to cause RNAi for CD44v9 and invasion assay, only two, spindled $\mathrm{G}_{\mathrm{s}} \alpha$ cells occupy this representative field of the membrane. In this experiment, invaded cells were $16 \%$ of those invading the control insert. Pores of membrane again have dye entrapment $(\times 200)$.

CD44v9 interference or Muc18 interference, had significantly less propensity to invade than their GFP-negative counterparts (Figure 5c).

Our findings by reverse-transcriptase PCR are comparable to those in other human tumors. Increased or altered CD44 variant mRNA is detectable in various tumors compared with benign tissue. This includes breast, lung, and pancreatic carcinomas. ${ }^{6,15,41}$ Other reported unusual and disorganized patterns of gene transcription include duplication or deletion of variant exons. ${ }^{15,21,42,43}$ One study found that over-abundance of CD44 transcripts containing portions of exons 11 (v6), and 12 (v7) as well as intron 9 occurred in $80 \%$ of colon cancers. ${ }^{43}$ The patterns were consistent and specific for tumor types, so their presence served as a diagnostic and possibly prognostic test. An abnormal CD44v8-v10 gene transcript was noted with high frequency in exfoliated cells in clinical diagnostic fluid specimens such as pleural effusion and urine. $^{5,22}$ Of 61 patients whose malignancy was missed on cytology (false negative), 11 had it diagnosed by RT-PCR for CD44v8-v10. ${ }^{21}$ Overexpression of CD44v8-v10 containing mRNA has been used as a serum, urinary, and tissue marker for bladder cancer ${ }^{21,22,38}$ and is an independent prognostic factor for colon cancer. ${ }^{23}$ Furthermore, RTPCR-enzyme linked immunosorbent assay has been used for detection of abnormal and overexpressed CD44 transcripts in colon cancer. ${ }^{33}$ Serum CD44 has been found to be of diagnostic and prognostic value in some tumors, ${ }^{44,45}$ so whether this applies to CD44 v9 mRNA or protein as a PC marker deserves further study. If CD44v9 protein is useful in PC detection and follow-up, it could compensate for some shortcomings of serum prostate-specific antigen 


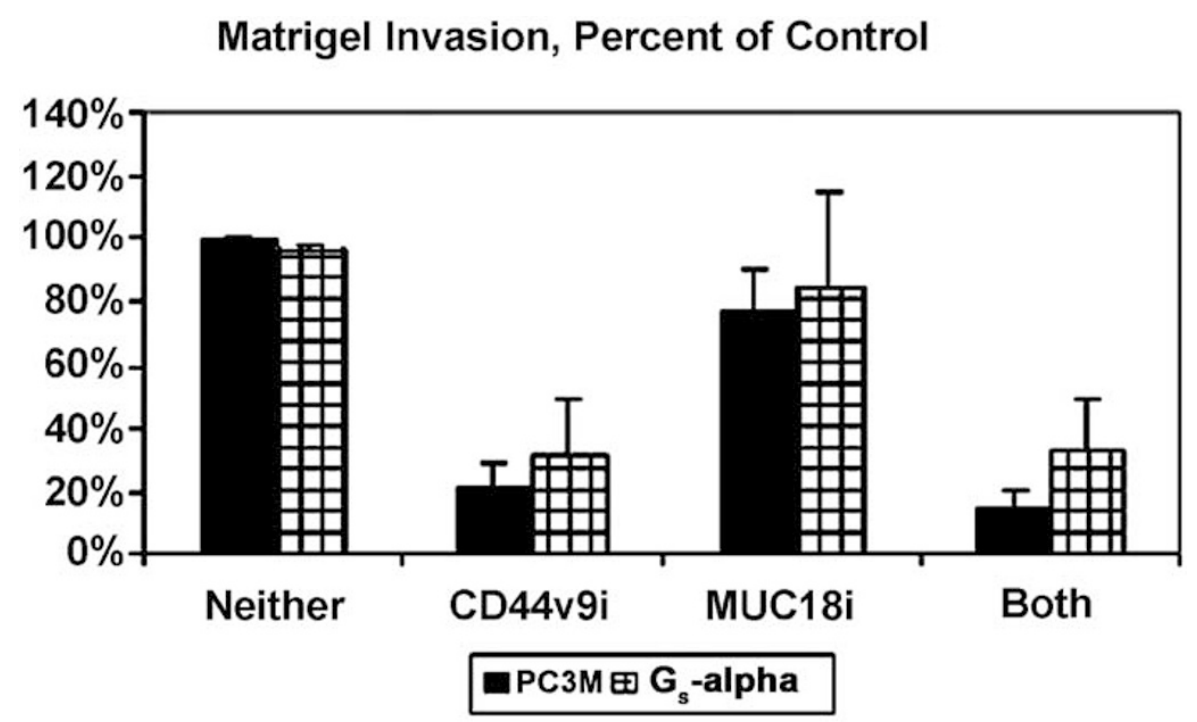

\section{Percent of Gs-Alpha Cells Invaded After Transfection \& FACS Cell Sorting}

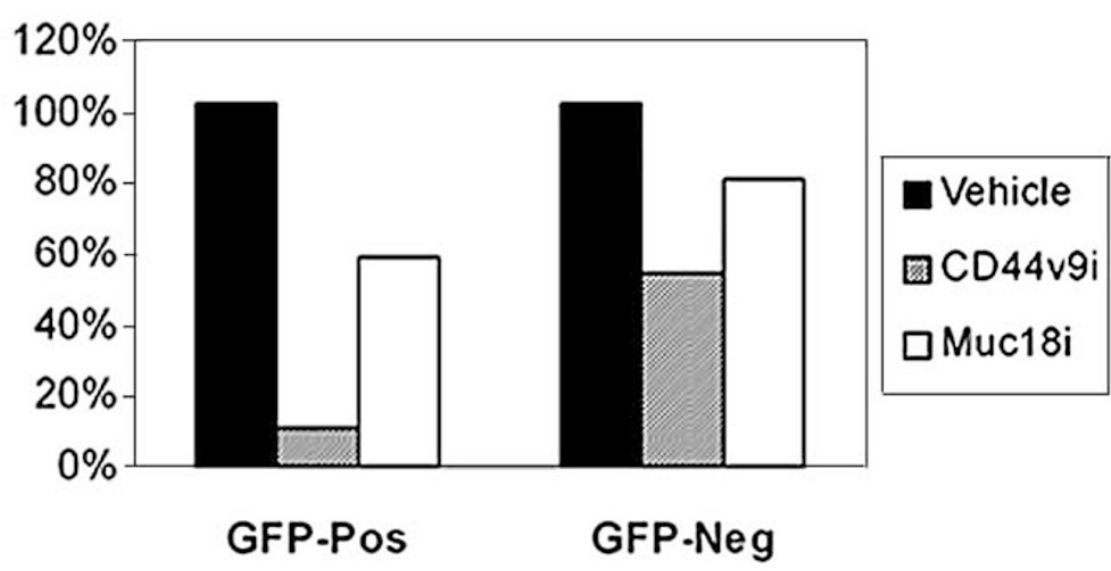

Figure 7 Matrigel Invasion Index of prostate cancer cells according to treatment. (a) Mean \pm standard deviation is shown for four experimental trials with PC3M cells and five trials with $\mathrm{G}_{\mathrm{s}} \alpha$ cells. All cells were transfected for GFP. RNAi for CD44v9 (CD44v9i), reduces Invasion Index of transfected PC3M cells to $21.6 \pm 7.0 \%$ of the index with vehicle alone $(P<0.001)$, and that of $\mathrm{G}_{\mathrm{s}} \alpha$ cells to $31.2 \pm 18.3 \%$ of vehicle control $(P<0.001)$. Cells undergoing Muc18i had Invasion Indices of $76.9 \pm 13.5 \%$ for PC3M cells $(P<0.05)$ and $84.8 \pm 29.9 \%$ for $\mathrm{G}_{\mathrm{s}} \alpha$ cells $(P=0.18)$ vs controls. Both CD44v9 and Muc18 RNAi reduced Invasion Indices similarl to the levels with CD44v9 RNAi alone $\left(P=0.001\right.$ for PC3M cells and $P=0.001$ for $\mathrm{G}_{\mathrm{s}} \alpha$ cells). A minority of the invaded cells were GFP-positive, by cell counts, $12.5-38.7 \%$ for the PC3M cells and 5.0-11.7\% for the $\mathrm{G}_{\mathrm{s}} \alpha$ cells. (b) In one experiment, FACS cell sorting was performed according to the GFP positivity. The percent of invasion by the GFP-positive cells receiving CD44v9 interference is less than the percent of invasion by the GFP-negative cells after the same RNAi treatments $(P<0.005)$ and the same is true after Muc18 interference $(P<0.025)$. Thus, enrichment for transfected cells yielded a less invasive population.

(PSA), in particular, its elevation in response to prostatic inflammation.

CD44v10 immunoreactivity was more frequent in tumor (89\% of samples) compared to benign tissue $(27 \%)$ in our tissue microarray. Benign tissue staining was also weaker than that of tumor. There was very little nonspecific staining. Our RT-PCR and sequencing (Figure 3e), did show benign and tumor samples both to have mRNA transcripts that contained only the v10 exon. ${ }^{25}$ The CD44v10 exon is much shorter than v9 (63 bps vs 204 bps). There is some evidence that the v10 moiety functions differently from v7-9 in attachment to hyaluronate. In dendritic cells, tumor necrosis factor $\alpha$ upregulates the expression of CD44v3-, v6-, and v9-containing isoforms. However, v3- and v6-containing forms were required for dendritic cell adhesion to immobilized hyaluronate, whereas anti-CD44v9 monoclonal antibodies were unable to block adhesion to hyaluronan. ${ }^{46}$ However, gastric carcinoma cells negative for CD44v5 and v6 exhibited higher hyaluronate binding than the corresponding posi- 
tive cells. ${ }^{47}$ CD44v9 also is involved in binding of myeloma cells to bone marrow stromal cells, but not to hyaluronate, and these effects were suggested to explain why CD44v9 expression worsens the prognosis in multiple myeloma. ${ }^{48}$ On the other hand, melanoma cell lines that had increased relative CD44v10 expression showed significantly higher migration rates on immobilized hyaluronate. ${ }^{49} \mathrm{In}$ endothelial cells, CD44v10 binds specifically to hyaluronate and interacts with Rho-kinase to play a role in intracellular calcium fluxes related to cell migration. ${ }^{50}$ Notably, hyaluronate is not a major component of Matrigel (which is mainly collagens, laminin, and proteoglycans); therefore, if the increased expression of CD44v10 in PC influenced Matrigel invasion, it probably interacts with other substituents.

An intriguing finding was the altered CD44v7-9 expression in $\mathrm{G}_{s} \alpha$ cells. $\mathrm{G}_{\mathrm{s}} \alpha$ cells were established (by Dr Girish Shah) from a metastatic type of PC3 cells, called PC3M, that was transfected to express a mutated $G_{s} \alpha$ protein that lacks GTPase activity and thus is constitutively active. Prostate cancer cells transfected with this $G_{s} \alpha$ show increased cAMP accumulation, increased DNA synthesis, faster proliferation, and greater invasiveness. ${ }^{28,29}$ A calcitoninlike peptide activates the $G_{s} \alpha$ signaling pathway. We have shown that calcitonin-like peptide is increased in PC in proportion to Gleason grade and tumor stage. $^{51}$ We showed that $\mathrm{G}_{\mathrm{s}} \alpha$ cells overexpress CD44v9 by Western blot analysis. This is, to our knowledge, the first link suggested between the hormonal signal transduction complex on the inner cytoplasmic membrane and a cell adhesion protein (which interacts with the cytoskeleton and thus may change cell shape). These preliminary data warrant further investigation in order to elucidate the mechanism between $G$ protein activation and CD44v7-v10 expression.

In conclusion, we have reinforced our previous finding of CD44v7-v10 overexpression in prostate cancer, shown this overexpression to apply to cells with constitutively active $\mathrm{G}_{\mathrm{s}} \alpha$ proteins, and gathered new evidence for the functional significance of CD44v7-v10 in invasion. All these findings open new pathways of investigation, such as gene therapy with RNAi against CD44 variants in cancer cells in vivo, and the design of small molecular inhibitors against CD44 variants.

\section{Acknowledgements}

Mr Ron Irby provided invaluable assistance with computer graphics. We thank Neal Benson for performing FACS cell sorting. We thank Karen Byer and Pat Glenton for allowing our use of facilities for protein preparation measurement.

This work was supported by American Cancer Society Research Scholar Grant RSG-02-157-01-
CCE and a Veterans Administration Merit Review Grant.

\section{References}

1 Iwase A, Shen R, Navarro D, et al. Direct binding of neutral endopeptidase 24.11 to ezrin/radixin/moesin (ERM) proteins competes with the interaction of CD44 with ERM proteins. J Biol Chem 2004;279: 11898-11905.

2 Bourguignon LYW, Zhu D, Zhu H. CD44 isoformcytoskeleton interaction in oncogenic signaling and tumor progression. Front Biosci 1998;3:D637-D649.

3 Goodison S, Tarin D. Clinical implications of anomalous CD44 gene expression in neoplasia. Front Biosci 1998;3:e89-e109.

4 Martyn V, Bell D, Jackson F, et al. Genomic structure of DNA encoding the lymphocyte homing receptor CD44 reveals at least 12 alternatively spliced exons. Proc Natl Acad Sci USA 1992;89:12160-12164.

5 Okamoto I, Morisaki T, Sasaki J, et al. Molecular detection of cancer cells by competitive reverse transcription-polymerase chain reaction analysis of specific CD44 variant RNAs. J Natl Cancer Inst 1998; 90:307-315.

6 Okamoto I, Tsuiki H, Kenyon LC, et al. Proteolytic cleavage of the CD44 adhesion molecule in multiple human tumors. Am J Pathol 2002;160:441-447.

7 Okamoto I, Kawano Y, Murakami D, et al. Proteolytic release of CD44 intracellular domain and its role in the CD44 signaling pathway. J Cell Biol 2001;155: 755-762.

8 Murakami D, Okamoto I, Nagano O, et al. Presenilindependent gamma-secretase activity medicates the intramembranous cleavage of CD44. Oncogene 2003; 22:1511-1516.

9 Gansauge F, Gansauge S, Rau B, et al. Low serum levels of soluble CD44 variant 6 are significantly associated with poor prognosis in patients with pancreatic carcinoma. Cancer 1997;80:1733-1739.

10 Taylor DD, Gercel-Taylor C, Gall SA. Expression and shedding of CD44 variant isoforms in patients with gynecologic malignancies. J Soc Gynecol Invest 1996;3: 289-294.

11 Iczkowski, KA, Pantazis CG, Collins J. The loss of expression of CD44 standard and variant isoforms is related to prostatic carcinoma development and tumor progression. J Urol Pathol 1997;6:119-129.

12 Nagabhushan M, Pretlow TG, Guo YJ, et al. Altered expression of CD44 in human prostate cancer during progression. Am J Clin Pathol 1996;106: 647-651.

13 De Marzo AM, Bradshaw C, Sauvageot J, et al. CD44 and CD44v6 downregulation in clinical prostatic carcinoma: relation to Gleason grade and cytoarchitecture. Prostate 1998;34:162-168.

14 Rall CJ, Rustgi AK. CD44 isoform expression in primary and metastatic pancreatic adenocarcinoma. Cancer Res 1995;55:1831-1835.

15 Woodman AC, Sugiyama M, Yoshida K, et al. Analysis of anomalous CD44 gene expression in human breast, bladder, and colon cancer and correlation of observed mRNA and protein isoforms. Am J Pathol 1996;149: 1519-1530.

16 Bourguignon LY, Zhu H, Shao L, et al. Rho-kinase (ROK) promotes CD44v(3,8-10)-ankyrin interaction 
and tumor cell migration in metastatic breast cancer cells. Cell Motil Cytoskeleton 1999;43:269-287.

17 Roca X, Mate JL, Ariza A, et al. CD44 isoform expression follows two alternative splicing pathways in breast tissue. Am J Pathol 1998;153:183-190.

18 Franzmann EJ, Weed DT, Civantos FJ, et al. A novel CD44 v3 isoform is involved in head and neck squamous cell carcinoma progression. Otolaryngol Head Neck Surg 2001;124:426-432.

19 Terpe H-J, Storkel S, Zimmer U, et al. Expression of CD44 isoforms in renal cell tumors. Am J Pathol 1996; 148:453-463.

20 Christ O, Gunthert U, Haas R, et al. Importance of CD44v7 isoforms for homing and seeding of hematopoietic progenitor cells. J Leukoc Biol 2001;69: 343-352.

21 Mortegani MP, Del Prete F, Gasbarri A, et al. Structural variability of CD44 molecules and reliability of immunodetection of CD44 isoforms using mAbs specific for CD44 variant exon products. Am J Pathol 1999;154:291-300.

22 Miyake H, Okamoto I, Hara I, et al. Highly specific and sensitive detection of malignancy in urine samples from patients with urothelial cancer by CDv8-v10/ CD44v10 competitive RT-PCR. Int J Cancer 1998;18: 560-564.

23 Yamaguchi A, Urano T, Goi T, et al. Expression of a CD44 variant containing exons 8 to 10 is a useful independent factor for the prediction of prognosis in colorectal cancer patients. J. Clin Oncol 1996;14: 1122-1127.

24 Dhir R, Thomas A, Krill D, et al. Immunohistochemical detection of isoforms of CD44 in metastatic and organ confined prostatic adenocarcinoma. Mod Pathol 1998;11:80A (Abstract).

25 Iczkowski KA, Bai S, Pantazis CG. Prostate cancer overexpresses CD44 variants 7-9 at the messenger RNA and protein level. Anticancer Res 2003;23: 3129-3140.

$26 \mathrm{Wu}$ G-J, Wu M-WH, Wang S-W, et al. Isolation and characterization of the major form of human MUC18 cDNA gene and correlation of MUC18 over-expression in prostate cancer cell lines and tissues with malignant progression. Gene 2001;279:17-31.

27 Wu G-J, Varma VA, Wu M-WH, et al. Expression of a human cell adhesion molecule, MUC18, in prostate cancer cell lines and tissues. Prostate 2001;48: 305-315.

28 Tomita K, van Boknoven A, van Leenders GJLH, et al. Cadherin switching in human prostate cancer progression. Cancer Res 2000;60:3650-3654.

29 Burger MJ, Tebay MA, Keith PA, et al. Expression analysis of $\delta$-catenin and prostate-specific membrane antigen: their potential as diagnostic markers for prostate cancer. Int J Cancer 2002;100: 228-237.

30 Sers C, Riethmuller G, Johnson JP. Muc18, a melanomaprogression associated molecule, and its potential role in tumor vascularization and hematogenous spread. Cancer Res 1994;54:5689-5694.

31 Chien J, Shah GV. Role of stimulatory guanine nucleotide binding protein $\left(G_{s} \alpha\right)$ in proliferation of PC-3M prostate cancer cells. Int J Cancer 2001;91: 46-54.

32 Chien J, Wong E, Nikes E, et al. Constitutive activation of stimulatory guanine nucleotide binding protein $\left(\mathrm{G}_{\mathrm{s}} \alpha \mathrm{QL}\right)$-medicated signaling increases invasiveness and tumorigenicity of PC-3M prostate cancer cells. Oncogene 1999;18:3376-3382.

33 Yoshida K, Goodison S, Sugino T, et al. Semiquantitative detection of abnormal CD44 transcripts in colon carcinomas by reverse transcription-polymerase chain reaction enzyme-linked immunosorbent assay (RT-PCR ELISA). Mol Diagn 1996;1:167-173.

34 Screaton GR, Bell MV, Jackson DG, et al. Genomic structure of DNA encoding the lymphocyte homing receptor CD44 reveals at least 12 alternatively spliced exons. Proc Natl Acad Sci USA 1992;89: 12160-12164.

35 Paddison PJ, Caudy MA, Bernstein E, et al. Short hairpin RNAs (shRNAs) induce sequence-specific silencing in mammalian cells. Genes Dev 2002;16: 948-958.

36 Kapadia SB, Brideau-Andersen A, Chisari FV. Interference of hepatitis $C$ virus RNA replication by short interfering RNAs. Proc Natt Acad Sci USA 2003;100: 2014-2018.

37 Laemmli UK. Cleavage of structural proteins during assembly of the head of bacteriophage T4. Nature 1970; 227:680-685.

38 Matsumura Y, Sugiyama M, Matsumura S, et al. Unusual retention of introns in CD44 gene transcripts in bladder cancer provides new diagnostic and clinical oncological opportunities. J Pathol 1995;177: 11-20.

39 McManus MT, Sharp PA. Gene silencing in mammals by small interfering RNAs. Nature Rev 2002;3: 737-747.

40 Elbashir SM, Harborth J, Lendeckel W, et al. Duplexes of 21-nucleotide RNAs mediate RNA interference in cultured mammalian cells. Nature 2001;411:494-498.

41 Wong LS, Cantrill JE, Odogwu S, et al. Detection of circulating tumour cells and nodal metastasis by reverse transcriptase-polymerase chain reaction technique. Br J Surg 1997;84:834-839.

42 Goodison S, Yoshida K, Sugino T, et al. Rapid analysis of distinctive CD44 RNA splicing preferences that characterize colonic cancer. Cancer Res 1997;57: 3140-3144.

43 Yoshida K, Bolodeoku J, Sugino T, et al. Abnormal retention of intron 9 in CD44 gene transcripts in human gastrointestinal tumors. Cancer Res 1995;55: 4273-4277.

44 Holzer G, Kittl E, Pfandelsteiner T, et al. Concentration of soluble CD44 standard and soluble CD44 variant v5 in the serum of patients with malignant bone tumors. Med Pediatr Oncol 2003;40:64-65.

45 Kopp R, Classen S, Wolf $\mathrm{H}$, et al. Predictive relevance of soluble CD44v6 serum levels for the responsiveness to second line hormone- or chemotherapy in patients with metastatic breast cancer. Anticancer Res 2001; 21:2995-3000.

46 Haegel-Kronenberger $\mathrm{H}$, de la Salle $\mathrm{H}$, Bohbot A, et al. Adhesive and/or signaling functions of CD44 isoforms in human dendritic cells. J Immunol 1998;161: 3902-3911.

47 Harn HJ, Shen KL, Liu CA, et al. Hyaluronate binding assay study of transfected CD44 v4-v7 isoforms into the human gastric carcinoma cell line SC-M1. J Pathol 1998;184:291-296.

48 Van Driel M, Gunthert U, van Kessel AC, et al. CD44 variant isoforms are involved in plasma cell adhesion to bone marrow stem cells. Leukemia 2002;16: 135-143. 
49 Yoshinari C, Mizusawa N, Byers HR, et al. CD44 variant isoform CD44v10 expression of human melanoma cell lines is upregulated by hyaluronate and correlates with migration. Melanoma Res 1999;9: 223-231.

50 Singleton PA, Bourguignon LY. CD44v10 interaction with Rho-kinase (ROK) activates inositol 1,4,5- triphosphate (IP3) receptor-mediated $\mathrm{Ca} 2+$ signaling during hyaluronan (HA)-induced endothelial cell migration. Cell Motil Cytoskeleton 2002;53: 293-316.

51 Iczkowski KA, Pantazis CG, Long J, et al. Expression of calcitonin-like peptide is increased in prostatic adenocarcinoma. J Urol Pathol 1998;8:135-147. 